Portland State University

PDXScholar

$12-12-1973$

\title{
A reexamination of the effects of prismatic displacement on pointing straight ahead
}

Anastasia Houndoumadi

Portland State University

Follow this and additional works at: https://pdxscholar.library.pdx.edu/open_access_etds

Part of the Other Psychology Commons

Let us know how access to this document benefits you.

\section{Recommended Citation}

Houndoumadi, Anastasia, "A reexamination of the effects of prismatic displacement on pointing straight ahead" (1973). Dissertations and Theses. Paper 2171.

https://doi.org/10.15760/etd.2168

This Thesis is brought to you for free and open access. It has been accepted for inclusion in Dissertations and Theses by an authorized administrator of PDXScholar. Please contact us if we can make this document more accessible: pdxscholar@pdx.edu. 


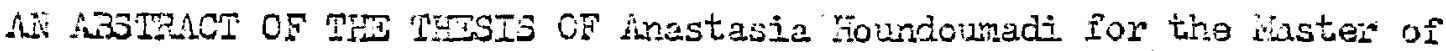
Arts in Psyshology presented Decemeer 1219,3

Title: A Resamination of the iffects of Prismatic Displacomant on Pointing straight Nhead.

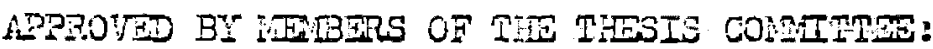

Gerald it. Surch, Csaimar

Jemes A. Paulson

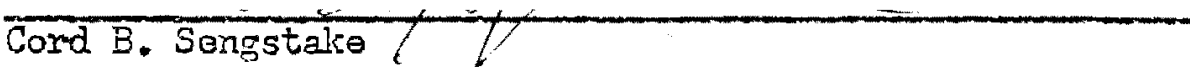

A fully counterbalanced extension of the Bauer ard Irstathiou (1955) study involved exposing 11 ss to lateral prismatie displacerrenc for five minutos and measuring their adaptation to it. The difference betroen pointings at a target taken before and aftor prismatic exposlire constitutes an adaptive sinjo.

The results of the present study iid not corfing tho first of

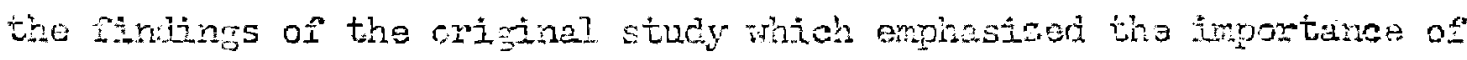
target sequence on the magnitude of the adaptive shipts. Painiting at 
a visible target does not seem to influence a susequent measurment of the straight ahead direction. Contrary to the Bauer and Efstatioiou findings and the predictions made by the sensorimotor inodel of prisnatic adaptation, mich their study supported, an adaptive shift in the straight ahead was found by the present study. 


\title{
A REEXAMINATION OF THE EFFECTS OF PRISMATIC DISPLACEMENT
}

ON POINTING STRAIGHT AHEAD

by

ANASTASIA HOUNDOUMADI

A thesis submitted in partial fulfillment of the requirements for the degree of

\section{MASTER OF ARTS \\ in \\ PSYCHOLOGY}

\author{
Portland State University \\ 1973
}


TO THE OFFICE OF GRADUATE STUDIES AND RESEARCH:

The members of the committee approve the thesis of

Anastasia Houndoumadi presented December 12, 1973.

Gerald M. Murch, Chairmań

James'A. Paulson

Cord B. Seng\$tqke

APPROVED;

Ronald E. Smith, Head, Department of Psychology ;

David T. Clark, Dean of Graduate Studies and Research

December 12,1973 
TABLE OF CONTENTS

PAGE

LIST OF TABLES ii i

LIST OF FIGURES iv

INTRODUCTION

METHOD

$$
\begin{aligned}
& \text { SUBJECTS . . . } \\
& \text { APPARATUS . . . } \\
& \text { PROCEDURE . . . . } \\
& \text { Pre-exposure } \\
& \text { Exposure } \\
& \text { Post-exposure }
\end{aligned}
$$

PROCEDURE . . . . . . . . . . . . . . . . . .

RESULTS

DISCUSSION

REFERENCES

APPENDIX 


\section{LIST OF TABLES}

TABLE

PAGE

I. Mean Differences in Inches Between Base Right and Base Left Prism Orientations........... 


\section{LIST OF FIGURES}

FIGURE

PAGE

1. General View of the Apparatus ............ 8

2. Experimental Design ............... . 11

3. General Block Diagram of the System . . . . . . . 19

4. Coordinate Position Measuring Device Using

Teledeltos Paper................. 20

5. Target Lamp Control Circuit ............ 21

6. Remote Variable Diopter Readout . . . . . . . . 21 


\section{INTRODUCTION}

One of the ways a person can enter an altered state of awareness is through distortion of her visual world. Using prisms, lenses, and mirrors one can introduce an apparent up-down inversion, right-1eft reversal, or lateral displacement of the visual field.

Early experimentation centered around the significance of an inverted retinal image for upright vision. A pioneer in this area was Stratton (1896, 1897), who using himself as a subject, wore a monocular lens system that reversed and inverted the visual field. In one experiment he wore the lenses for three days and in another for eight days. Although he never saw the world "right side up," he maintained that his experiments supported the empirical theory of perception stating that we see the world upright because we learn that it is so and the orientation of the retinal image is irrelevant.

Based on the assumption that the process leading to the perceptual development in the infant is identical to that leading to adaptation to an optically transformed world in the adult, Kohler (1964) conducted extensive research at the University of Innsbruck in Austria involving reversal, inversion, and angular displacement. His $\underline{\text { S}}$ s wore optically distorting devices for long periods of time sometimes exceeding a month, because he felt that an $\underline{S}$ should be given enough time to replace old habits with new ones.

Un1ike earlier research, current experiments do not aim at determining whether an $\underline{\mathrm{S}}$ will eventually come to perceive the world 
normal again if she is exposed to the optical distortion for a sufficiently long time. Rather the emphasis now is on the way the a1tered visual input modifies the perceptual system. For that reason it is not necessary for the $\underline{S}$ to wear the optically distorting devices for several days.

A line of research that has become increasingly popular and to which we will restrict our attention, is the study of the effects produced by lateral displacement of the visual field. Von Helmholtz is considered the first to have conducted an experiment of this kind as early as 1867 using wedge prisms.

When a person is looking through wedge prisms all the objects within her field of view appear to be shifted to one side, the direction of displacement being towards the apex of the prisms. For instance, if she attempts to point at an object while wearing prisms which displace her apparent visual field to the left, she will miss because she points at the displaced image and not the object itself. With practice, however, she misses 1 ess and 1 ess until she can accurately point at the object. Once the prisms are removed and she tries again to point at the object she misses it by pointing too far to the right.

Both the gradual improvement exhibited during pointing while wearing the prisms, and the after effect observed upon the removal of the prisms, demonstrate that the $\underline{S}$ adapted to the new perceptual environment. Rock (1966) defines adaptation as a reduction of the perceived distortion such that if adaptation were complete the world would appear exactly the way it did before it was optically transformed. 
The typical short-term experiment investigating prismatic adaptation involves a comparison between pre-exposure and post-exposure behavior. In this case, an $\underline{\mathbf{S}}$ is asked to point at a target before and after exposure to prismatic displacement. The difference between preexposure and post-exposure markings is called an adaptive shift if it is in the direction of the prismatic displacement and maladaptive if it is in the opposite direction. This shift provides a quantitative measure of adaptation.

The nature and mechanisms of this perceptual adaptation have been the subject of many theories. For the purpose of the present study only two major models will be reviewed, the "proprioceptive" and the "sensorimotor."

According to the proprioceptive model proposed by Charles $S$. Harris (1963, 1965), when a person wearing prisms views her hand pointing at a target she is confronted by two discrepant sources of information about her reaching movement. One source is visual in nature and one proprioceptive. The hand is seen at one place while it "feels" to be at another. It is maintained by this model that during exposure the $\underline{S}$ eventually comes to feel that her hand is in a position consistent with the visual information. According to Harris, the felt position of the hand which is seen through the prisms, changes in relation to the rest of the body. When vision and proprioception give conflicting information, vision dominates over proprioception. If the prismatic displacement is removed after adaptation, the $\underline{S}$ will exhibit an adaptive shift because the newly acquired felt position of the hand misguides her. 
The other major model to be reviewed is the sensorimotor which is proposed by Richard Held and his co-workers (Held and Freedman, 1963). The emphasis here is on the process underlying adaptation. According to this model the CNS constantly correlates each motor output, which consists of the efferent signals to the muscles, with the resulting sensory feedback. If one wears prisms, the established central correlation between the motor output and the sensory input is disturbed. Through successive movements, however, a new "recorrelation" between the motor output and the distorted visual input is established.

In analyzing the act of pointing at a target, the existence of an outside target against which the $\underline{\mathbf{S}}$ can anchor head orientation is stressed as very important in this model.

The act of reaching for a visible target consists in orienting the arm so that the direction of a line drawn from hand to eye matches the actual or potential direction indicated by the head when it is oriented to the target. (A. Efstathiou, et al., 1967, p. 116.)

While for the proprioceptive model adaptation meant a change in the felt position of the hand, here it is defined as a change in the matched orientations between arm and head.

It is difficult to compare and contrast the two models, especially if one considers that the one--the proprioceptive--is talking about the end product of adaptation, while the other--the sensorimotor--deals more with the mechanism of adaptation. The difference, however, between the two models can be made clearer by examining the predictions made by each.

An adaptive shift is predicted when pointing at a visible target, an auditory signal, or the contralateral hand by both the proprioceptive 
(Harris, 1963; Harris, 1965), and the sensorimotor model (Efstathiou and Held, 1964). According to the proprioceptive model, when the $\underline{\mathbf{S}}$ points following prismatic exposure she is proprioceptively informed that she is pointing directly to the target when actually she is missing because the felt position of the hand has been altered. For the sensorimotor model, a visible target, an auditory signal, and the contrallateral hand exist in space as well defined targets towards which the $\underline{\mathbf{S}}$ can orient her head while pointing. Thus she will employ the new matched orientations between arm and head that were established during exposure when arm movement was correlated with a displaced visual feedback.

In an experiment that demonstrates the difference in the predictions made by each model, the $\underline{S}$ was trained during pre-exposure to locate her hand at various positions that were known to her only by the felt position of the hand. Following prismatic exposure she was asked to reestablish with the adapted hand the remembered positions relying only on postural cues. (A. Efstathiou, et al., 1967). Based on the proprioceptive model, the $\underline{S}$ should show an adaptive shift as the felt position of the hand must have changed during exposure. No adaptive shift, however, should be found according to the sensorimotor model. This is so because in reestablishing these positions, which do not constitute an external target, the new matched arm-head orientations that developed during exposure are not used. No adaptive shift was found in this experiment confirming thus the predictions of the sensorimotor model.

Further the two models differ most clearly in their predictions about the existence of an adaptive shift in the straight ahead 
direction. That is when the $\underline{\underline{S}}$ is asked to point with her eyes closed towards her subjective straight ahead. The proprioceptive model predicts an adaptive shift and results conforming to this prediction are reported by Harris (1963). As the straight ahead is not considered a specific external target to which the $\underline{\mathrm{S}}$ can orient her head, no adaptive shift is predicted by the sensorimotor model. This prediction was confirmed by the findings reported by Bauer and Efstathiou (1965) in disagreement to the earlier findings reported by Harris (1963). Bauer and Efstathiou reasoned that Harris obtained an adaptive shift in the straight ahead direction because he interspersed in his experiment various kinds of pointings--visible target, auditory target, and straight ahead. As a result of this the straight ahead, being an ambiguous target by itself, was probably "defined" for the $\underline{s}$ by the target preceding it. Accordingly, Bauer and Efstathiou found in their study that an $\underline{\mathbf{S}}$ showed an adaptive shift in the straight ahead direction only if she had already pointed at a visible target. The $\underline{\mathbf{S}}$ gave a maladaptive shift if she pointed straight ahead immediately following exposure. This maladaptive shift was attributed to the ambiguity of the straight ahead as a target. 1

The aforementioned Bauer and Efstathiou study is crucial because in dealing with the problem of the existence of an adaptive shift when pointing straight ahead, which is a point on which the two models clearly differ in their predictions, it yielded findings supporting the sensorimotor model. Furthermore they provided evidence that Harris' earlier findings (1963) were an artifact of his design. The two

\footnotetext{
${ }^{1}$ Efstathiou, Aglaia, 1973 personal communication.
} 
interrelated major findings of the Bauer and Efstathiou study are: (1) the influence exercised by the visible target in defining the straight ahead, (2) the absence of an adaptive shift in the straight ahead.

These findings are significant because they seriously question the applicability of the proprioceptive model. Arguments were raised, however, regarding the validity of the findings because the experimental design was not perfectly counterbalanced. It was decided therefore to undertake the present study in order to determine whether the same pattern of results would be obtained if a counterbalanced design is used.

In the Bauer and Efstathiou study the $\underline{S} s$ made three sets of pointings in the following way. If they had pointed at a visible target before exposure, then the sequence of the post-exposure markings was visible target-straight ahead-visible target. If they had pointed straight ahead, then the sequence was straight ahead-visible targetstraight ahead. Both conditions were done under base right (BR) and base left (BL) prism orientations. The two conditions added by the present study are a visible target-straight ahead-visible target sequence following straight ahead pointing during pre-exposure, and a straight ahead-visible target-straight ahead following visible target pointing in pre-exposure. Further all these conditions were also run under a no-prism (NP) condition which was absent in the original study. 


\section{METHOD}

\section{SUBJECTS}

Eight female and three male college undergraduates between age 21 and 28 served as $\underline{\mathbf{s} s}$ for 15 minutes eqvery day for 12 days. The minimum time interval between two trials was 24 hours. All $\underline{S}$ s were completely naive as to the purpose of the experiment.

\section{APPARATUS}

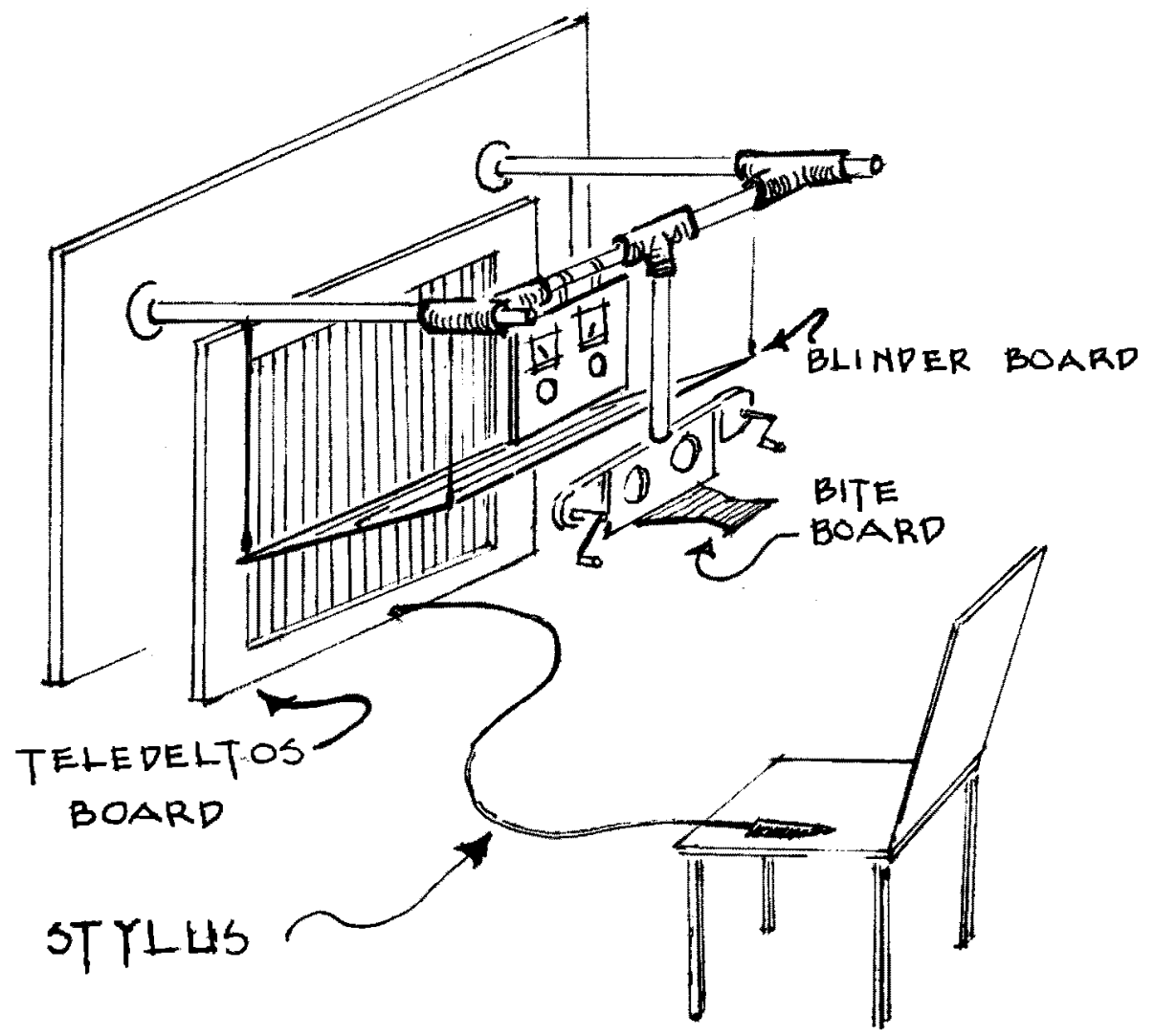

Figure 1. General view of the apparatus. 
The S was seated facing a $24^{\prime \prime} \times 24^{\prime \prime}$ board where miniature light bulbs were mounted at a distance of $27^{\prime \prime}$. As these lights served as the visible targets, the experiment was conducted in the dark. Throughout the experiment the $\underline{\mathbf{S}}$ 's head was held stationary by a biteboard. The $\underline{\mathbf{S}}$ looked through goggles in which prisms had been mounted. The degree of displacement introduced by the prisms was $11^{\circ}$ to the right or left. The goggles were equipped with blinders which were lowered whenever the S was asked to close her eyes.

The $\underline{S}$ pointed with a stylus at the board which was made out of Teledeltos paper (Bauer, et a1., 1969). When the stylus contacted the board it measured voltages proportional to the horizontal and vertical coordinates of the contact point. Those measures were read by a PDP-11/20 computer in an adjoining room and printed out on an ASR-33 teletype. Only the measures on the horizontal dimension were used in the computation of the present data.

During pre-exposure and post-exposure markings, the $\underline{\mathrm{S}}$ was prevented from seeing her hand pointing by a black blinder board which was removed during exposure by lifting it up at one side.

A more detailed description of the apparatus may be found in the Appendix,

\section{PROCEDURE}

\section{$\underline{\text { Pre-exposure }}$}

While looking through $0^{\circ}$ prismatic displacement, the $\underline{\mathrm{S}}$ was asked to extend her arm at shoulder height and touch the board with the stylus directly below the visible target. In other conditions she was asked 
to close her eyes and point straight ahead. Straight ahead was defined for the $\underline{S}$ as the extension of her nose. In all conditions she was asked to make 10 marks.

\section{$\underline{\text { Exposure }}$}

The blinder board was removed and the target lights were turned on. Altogether there were 7 lights; 3 out of the 7 were switched on in any condition such that they always appeared to be in the center of the board even if the $\underline{\mathbf{S}}$ was looking through the prisms. The $\underline{\mathbf{S}}$ was asked to point randomly at each of the lights an approximate equal number of times for 5 minutes. The movement of the $\underline{S}$ was the same as during preexposure. She extended her arm, pointed with her index finger, and then dropped it to her lap. Moreover, she was instructed to vary the starting position of each pointing.

\section{$\underline{\text { Post-exposure }}$}

With the prisms adjusted to $0^{\circ}$ displacement and the blinder board replaced, the $\underline{\mathbf{S}}$ made 3 sets of 10 markings in the sequence straight ahead-visible target-straight ahead or visible target-straight aheadvisible target.

The complete design can be seen in Figure 2. Each $\underline{\mathrm{S}}$ served in all conditions, the sequence being determined randomly.

The NP conditions were included in order to provide a baseline against which all shift values could be compared. 


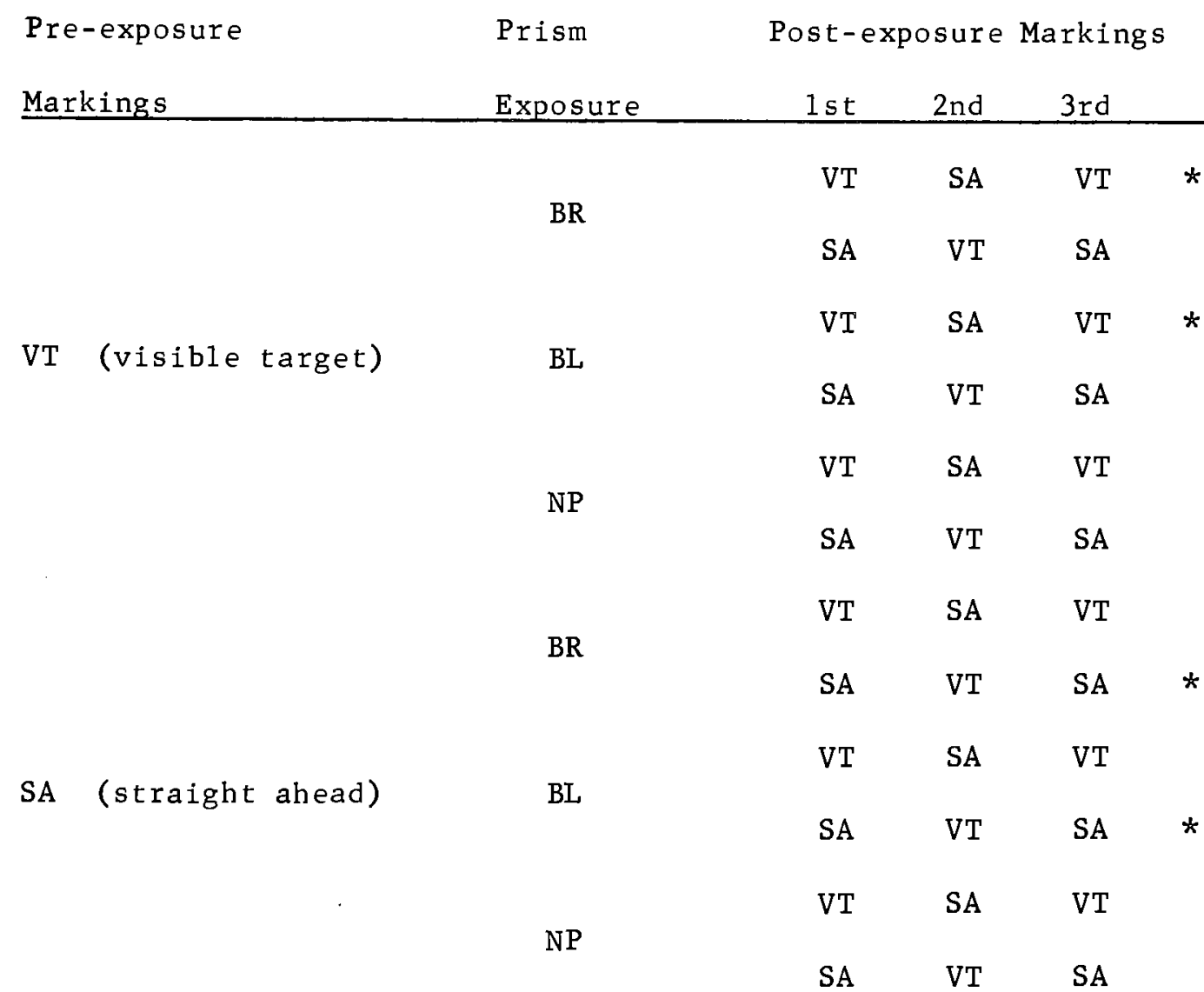

\footnotetext{
*These conditions were also present in the Bauer and Efstathiou study.
}

Figure 2. Experimental design. 


\section{RESULTS}

The adaptive shift in inches for each type of target was obtained by subtracting post-exposure from pre-exposure markings. The shifts obtained in the four NP control conditions, which constituted the baseline, were subtracted from the mean shift for $B R$ and $B L$ prism orientations. The obtained values appear in Table I.

A series of $t$-tests were conducted to test the hypothesis that the position of straight ahead in the sequence of post-exposure markings is critical. If the hypothesis is true, then the magnitude of shifts exhibited in the straight ahead should be greater if the markings occupy the second or third position in the sequence of post-exposure markings $\left(\mathrm{SA}_{2}\right.$ or $\left.\mathrm{SA}_{3}\right)$, than when they are first $\left(\mathrm{SA}_{1}\right)$. If the magnitude of the shift is found to be significantly enhanced, that would mean that $\mathrm{SA}_{2}$ and $\mathrm{SA}_{3}$ were influenced by the preceding $\mathrm{VT}_{1}$ and $\mathrm{VT}_{2}$ pointings respectively. A t-test was computed for the difference between $\overline{\mathrm{SA}}_{1}$ and $\overline{\mathrm{SA}}_{2}, \overline{\mathrm{SA}}_{1}$ and $\overline{\mathrm{SA}}_{3}, \overline{\mathrm{SA}}_{2}$ and $\overline{\mathrm{SA}}_{3}$, where $\overline{\mathrm{SA}}_{1}$ is the mean of all $\mathrm{SA}_{1}$ values e.t.c. None of the obtained values reached significance ( $p>.05)$. 
TABLE I

MEAN DIFFERENCES IN INCHES BETWEEN BASE RIGHT AND BASE LEFT PRISM ORIENTATIONS

Nature \& Sequence of Markings

Pre-exposure Post-exposure

$\begin{array}{lll}\mathrm{VT}_{\mathrm{p}} & : & \mathrm{VT}_{1} \mathrm{SA}_{2} \mathrm{VT}_{3} \\ \mathrm{VT}_{\mathrm{p}} & : & \mathrm{SA}_{1} \mathrm{VT}_{2} \mathrm{SA}_{3} \\ \mathrm{SA}_{\mathrm{p}} & : & \mathrm{VT}_{1} \mathrm{SA}_{2} \mathrm{VT}_{3} \\ \mathrm{SA}_{\mathrm{p}} & : & \mathrm{SA}_{1} \mathrm{VT}_{2} \mathrm{SA}_{3}\end{array}$

Obtained Shift in Inches

\begin{tabular}{lll}
1 st & 2nd & 3rd \\
\hline 3.99 & 2.81 & 3.34 \\
3.00 & 2.34 & 2.96 \\
3.40 & 1.79 & 2.53 \\
1.20 & 1.52 & 1.01
\end{tabular}




\section{DISCUSSION}

The data reported in Table I indicate that an adaptive shift was obtained in all conditions. By comparison Bauer and Efstathiou (1965) reported shifts of $2.54,1.66,1.98$, for the $\mathrm{VT}_{\mathrm{p}}: \mathrm{VT}_{1} \mathrm{SA}_{2} \mathrm{VT}_{3}$ condition, and -1.81 (maladaptive shift), $1.77,0.83$ for the $\mathrm{SA}_{\mathrm{p}}: \mathrm{SA}_{1} \mathrm{VT}_{2} \mathrm{SA}_{3}$ condition.

It appears that the adaptive shift obtained in the present study was stronger than the one reported by Bauer and Efstathiou by a factor of 1.32 on the average for the $\mathrm{VT}_{\mathrm{p}}: \mathrm{VT}_{1} \mathrm{SA}_{2} \mathrm{VT}_{3}$ condition. Their second condition $\left(\mathrm{SA}_{\mathrm{p}}: \mathrm{SA}_{1} \mathrm{VT}_{2} \mathrm{SA}_{3}\right.$ ) cannot be directly compared to the present study's as our findings are in the opposite direction. A reason for the stronger effect may be the different procedures followed during exposure in the two experiments. In the original study the $\underline{\mathbf{S}}$ simply saw her hand moving back and forth on a uniform panel. The procedure followed in the present experiment enabled the $\underline{\mathrm{S}}$ to get more feedback, as she could see her hand pointing at the targets. Another possible source for the weaker effects obtained by Bauer and Efstathiou may have stemmed from the duration of their experimental sessions which lasted 30 minutes as opposed to 15 minutes in the present study. Their sessions were longer because pre-exposure practice pointings were included in their design. The weaker effects therefore, may be due to the longer duration, or to the pre-exposure practice pointings, or some combination of the two. 
By comparing the present findings with the Bauer and Efstathiou's, it $c$ an be seen that the first of their major findings, namely the influence of the visible target on the definition of the straight ahead, is not confirmed. As reported in the Results section, the magnitude of the adaptive shift obtained in the straight ahead pointings was not found to vary significantly depending on the position it occupied in the sequence of post-exposure markings (see Table I). The pointings made in the straight ahead direction immediately following exposure $\left(\mathrm{SA}_{1}\right)$ are not significantly different from the ones made after having pointed at a visible target $\left(\mathrm{SA}_{2}\right.$ or $\left.\mathrm{SA}_{3}\right)$.

Furthermore, the results of the present study fail to replicate the second finding of the Bauer and Efstathiou study, i.e., the absence of an adaptive shift in the straight ahead. A clear adaptive shift of 1.20 inches (see Table I) was obtained in the present study. This is quite different from the maladaptive shift of -1.31 obtained in $\mathrm{SA}_{\mathrm{p}}: \mathrm{SA}_{1}$ by Bauer and Efstathiou.

In line with the sensorimotor model's predictions, the explanation offered by Bauer and Efstathiou regarding the absence of an adaptive shift in the straight ahead direction, is that the straight ahead does not exist by itself as a well defined target in space. The present study provided evidence that the straight ahead exists as a target by itself and is fairly stable, i。e, not significantly influenced by the presentation of a visible target.

Straight ahead and visible target both seem to exist as targets but they are qualitatively different. The one exists outside the $\underline{s}$ in a fixed location (visible target), while the other (straight ahead) is 
determined by the drection to which the observer is oriented, and is not fixed in space. These two kinds of targets seem to be differentially affected by prismatic displacement: the $\underline{S}^{\prime} s$ perceptual straight ahead seems to be less influenced than the perception of a visible target (See Table I).

Thus a potential confounding factor in studies of prismatic displacement utilizing different targets for obtaining adaptive shifts may be the assumption that the targets are qualitatively identical. As the process underlying prismatic adaptation has not yet been adequately explained, different targets should not be considered interchangeable. Post-exposure measurements obtained in the straight ahead direction cannot be meaningfully subtracted from pre-exposure measurements of visible target pointings and vice versa.

In conclusion, the present findings failed to demonstrate the presence of a significant influence exercised by the visible target in defining the straight ahead direction. Moreover, the results obtained in this study are not commensurate with the predictions of the sensorimotor model regarding the absence of an adaptive shift in the straight ahead; they do agree, however, with the predictions made by the proprioceptive model in this respect. 


\section{REFERENCES}

Bauer, J. Jr., and Egli Efstathiou, "Effects of adaptation to visual displacement on pointing 'straight ahead'," Paper read at Eastern Psychological Association, Atlantic City, April 1965.

Bauer, J. Jr., G. D, Woods, and R. Held, "A device for rapid recording of positioning responses in two dimensions," Behavior Research Methods and Instruments, 1969, 1, 157-159.

Efstathiou, Aglaia, and R. Held, "Cross-modal transfer of adaptation to eye-hand rearrangement," Paper read at Eastern Psychological Association, Philadelphia, April 1964.

Efstathiou, Aglaia, J. Bauer, M. Greene, and R. Held, "Altered reaching following adaptation to optical displacement of the hand," Journal of Experimental Psychology, 1967, 73, 113-120.

Harris, C. S. "Adaptation to displaced vision: visual, motor, or proprioceptive change?", Science, 1963, 140, 312-813.

Harris, C. S., "Perceptual adaptation to inverted, reversed, and displaced vision," Psychological Review 1965, 72, 419-444.

Held, Richard, and S. J. Freedman, "Plasticity in human sensorimotor control," Science, 1963, 142, 455-462.

Helmholtz, H. von, Treatise on Physiological Optics, (Trans. \& Ed, by J. P. C. Southall), vol. 3, New York: Dover 1962.

Kohler, I., "The formation and transformation of the perceptual world," Trans. by H. Fiss, Psychological Issues, 1964, 3, No. 4, 1-173.

Rock, Irvin, The Nature of Perceptual Adaptation, New York: Basic Books, Inc., 1966.

Stratton, G. M., "Some preliminary experiments on vision without inversion of the retinal image," Psychological Review, 1896, 3, 611-617.

Stratton, G. M., "Vision without inversion of the retinal image," Psychological Review, 1897, 4, 341-360, 463-481. 


\section{APPENDIX}

\section{COORDINATE MEASURING DEVICE USING TELEDELTOS PAPER ${ }^{1}$}

The coordinate position of the probe, when it contacts the surface of the Teledeltos paper, is indicated by a voltage which is sensed at the point of contact. There is a unique set of voltages for each paint on the paper. This is accomplished by means of silicon diodes which unilateralize current flow through the Teledeltos paper. The sensed voltage is processed by means of an Analog to Digital converter. The digital output of the A/D converter is fed into a PDP-11/20 computer which causes the coordinate information to be printed on an ASR-33 Teletype.

Diodes are connected to the Teledeltos paper in such a manner that on positive alternations of the input voltage from the $800 \mathrm{~Hz}$ oscillator, current flows from left to right and on negative alternations, it flows from bottom to top. Since the Teledeltos paper has a uniform resistivity over its surface, there is a uniform voltage gradient from left to right or top to bottom depending on the polarity of alternating input voltage.

The voltage which appears at the probe is fed in both direct and inverted form to separate channels of the A/D converter. Since the A/D converter has a unipolar input, it responds only to positive voltages.

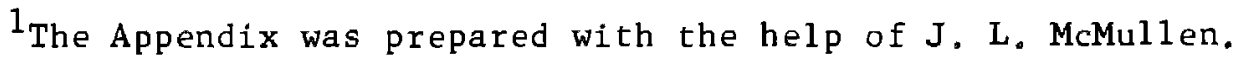


For this reason, at any given time, it measures a voltage which is proportional to either the left-to-right or the bottom-to-top position. There is another signal which is taken from the wiper of the amplitude potentiometer. This signal is used as a synchronizing signal and is fed to a third channel of the $A / D$ converter. The synchronizing signal provides positive indication to the computer that the " $\mathrm{x}$ " coordinate is being sensed.

The A/D converter, which is under program control from the PDP-11/20 computer, reads first the direct signal, and then the inverted signal. As soon as the input voltage exceeds a certain threshold level (typically. 15 volts), the A/D converter takes 500 to 1,000 samples. The highest voltage seen during the sampling period is printed out on the teletype under the " $x$ " or " $y$ " heading depending on whether it is reading the direct or inverted signal.

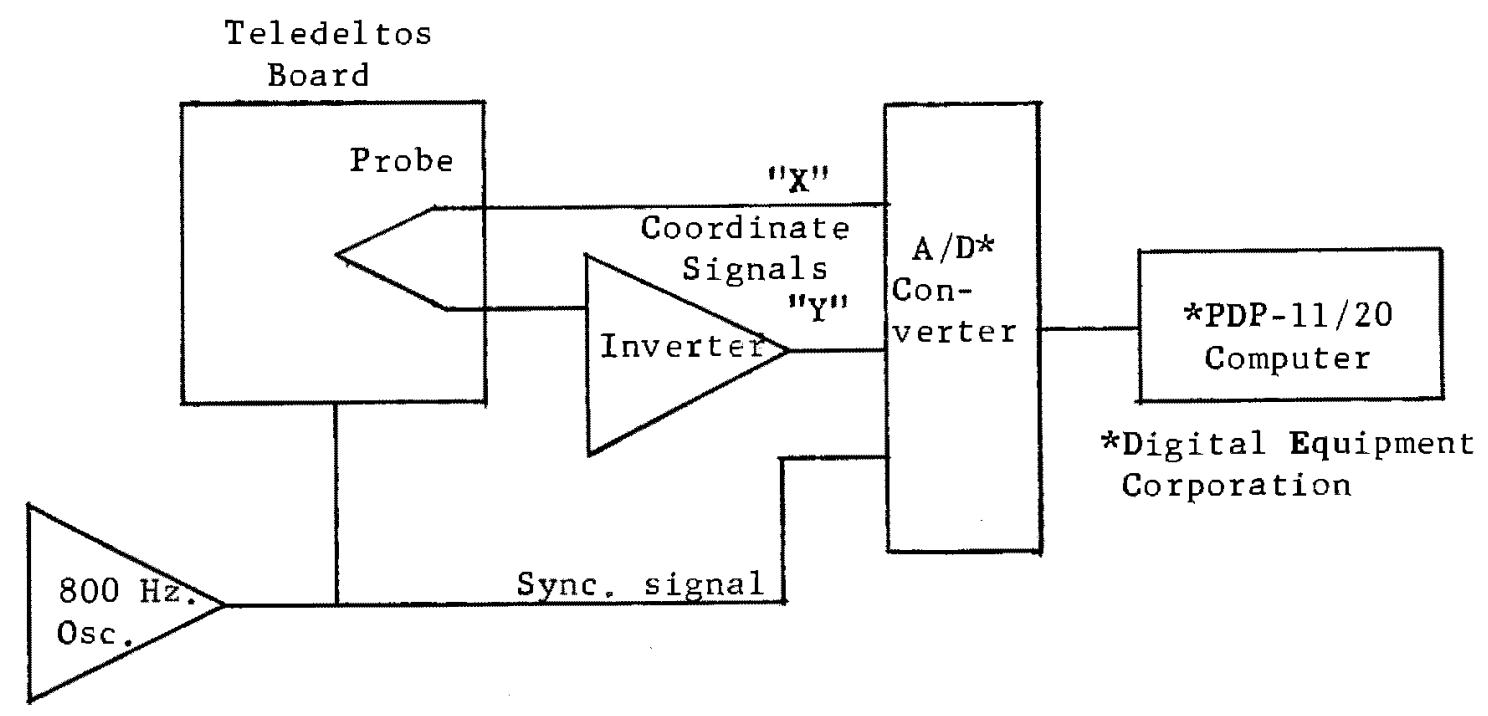

Figure 3. General block diagram of the system. 


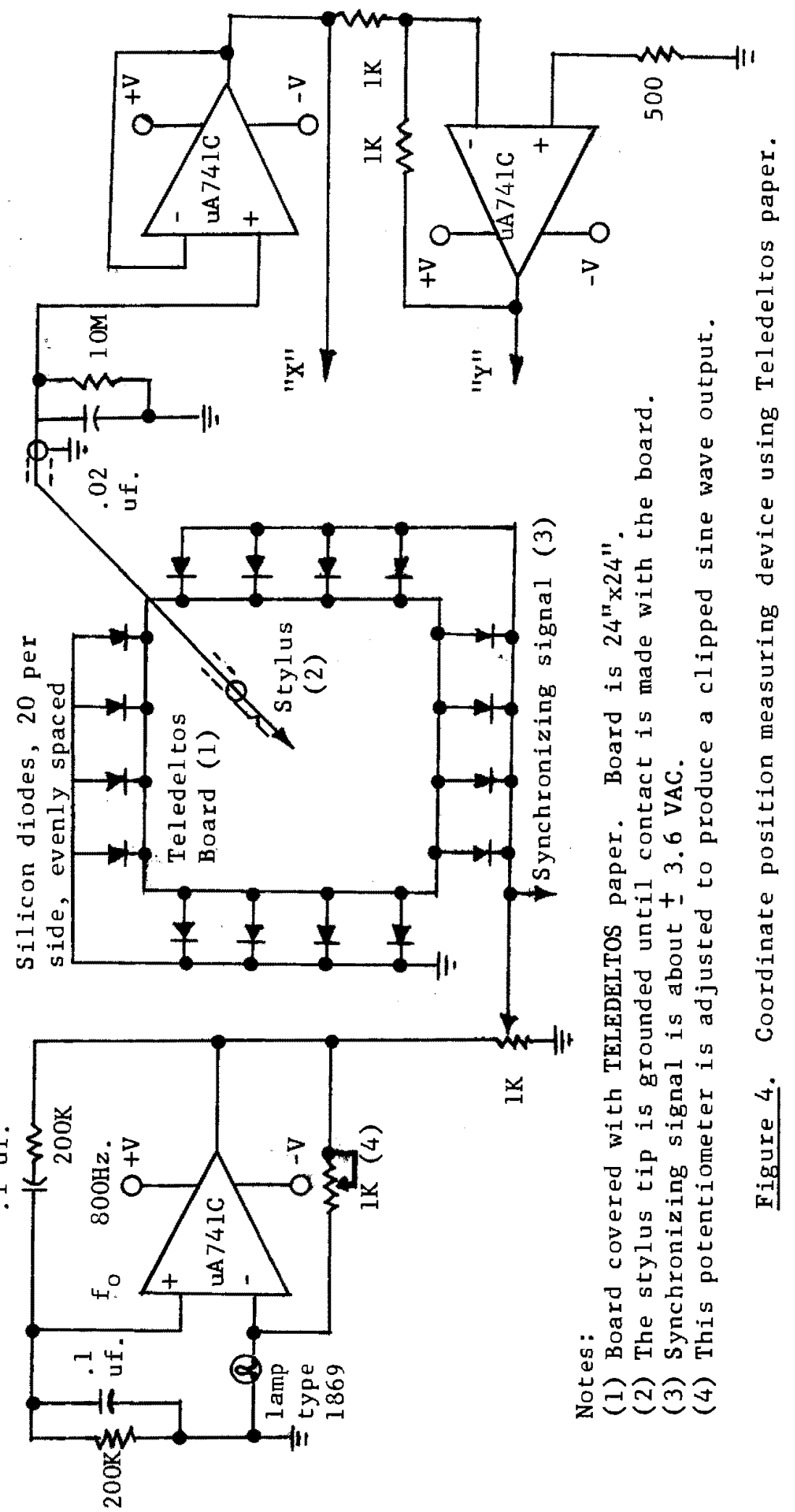




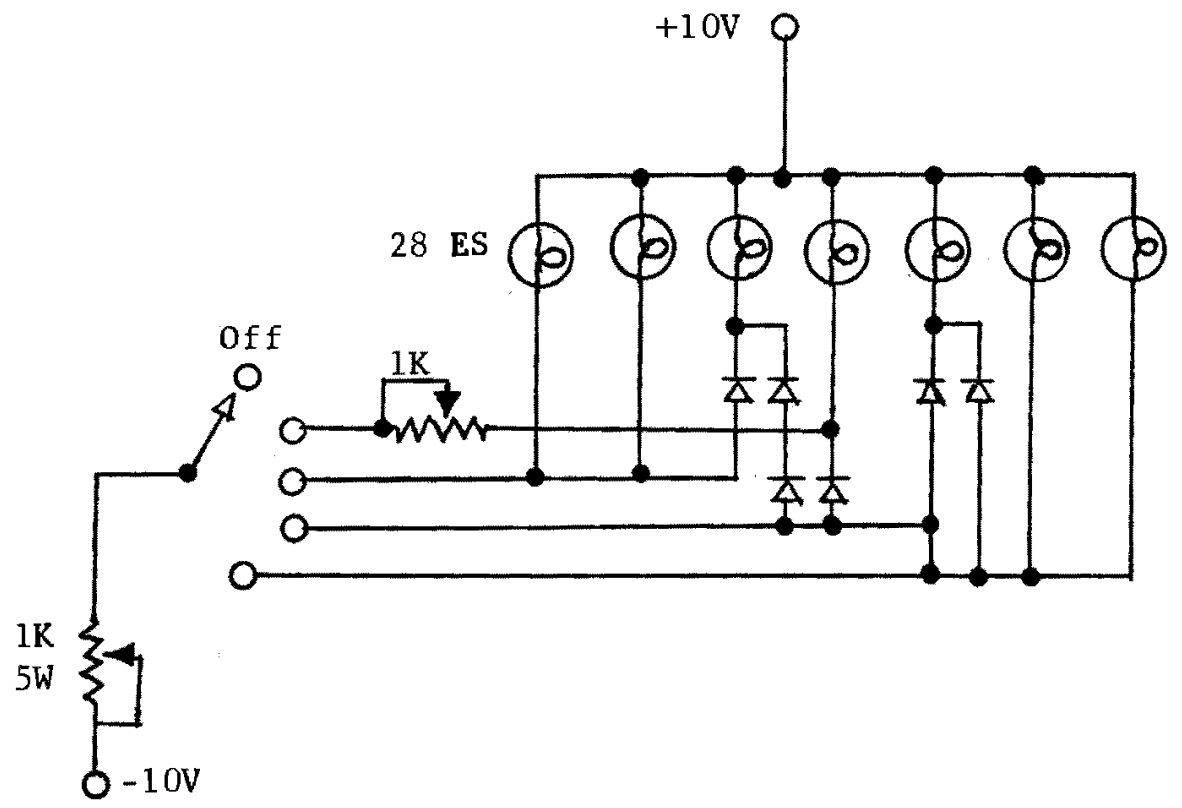

Figure 5. Target lamp control circuit.

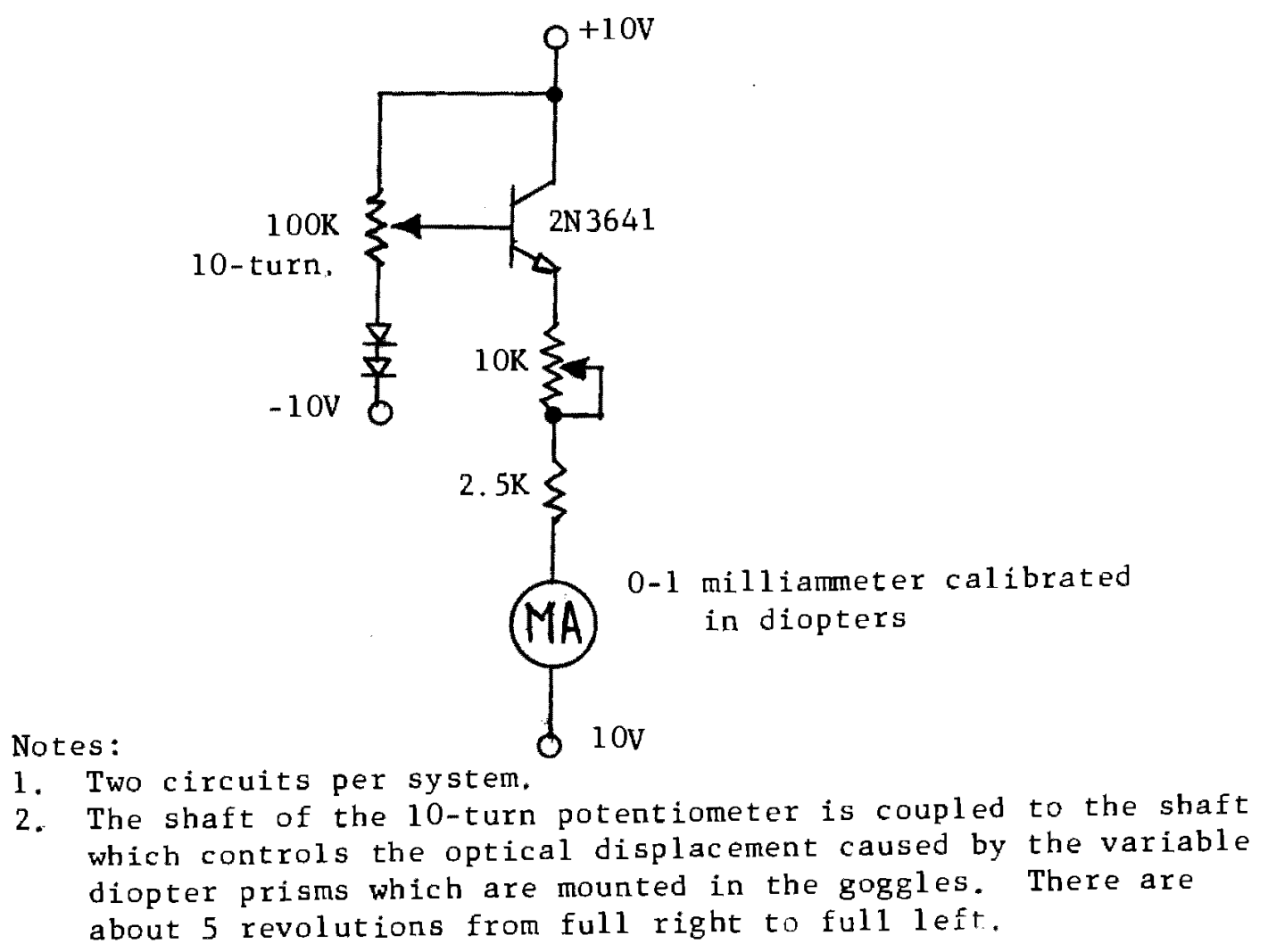

Figure 6. Remote variable diopter readout. 